\title{
Effects of Body Hair on College-Age Males on Body Composition Measurements by BOD POD
}

\author{
Scott Murr ${ }^{*}$, Alex Hultstrom \\ Health Sciences Department, Furman University, Greenville, USA \\ Email address: \\ scott.murr@furman.edu (S. Murr), alexandra.hultstrom@duke.edu (A. Hultstrom) \\ ${ }^{*}$ Corresponding author
}

\section{To cite this article:}

Scott Murr, Alex Hultstrom. Effects of Body Hair on College-Age Males on Body Composition Measurements by BOD POD. American Journal of Sports Science. Vol. 9, No. 2, 2021, pp. 43-50. doi: 10.11648/j.ajss.20210902.13

Received: May 21, 2021; Accepted: June 7, 2021; Published: June 15, 2021

\begin{abstract}
Body composition measurements by BOD POD account for the effects of trapped isothermal air in hair on the scalp by having the subject wear a swim cap to compress the hair on the head. However, there are no recommendations that account for the effects of trapped isothermal air in hair elsewhere on the body. The purpose of this investigation was to examine the effect of body hair on body composition measurements by BOD POD. To assess the impact of body hair on body composition measurements, BOD POD measurements were performed in two conditions: wearing single layer compression shorts (CS) apparel with a swim cap (recommended by manufacturer) and wearing single layer limb length compression (LC) apparel with the same swim cap. The order of apparel was conducted in random order to avoid any potential order effect. Fifty male college-age males (age $19.96 \pm 1.32$ years) volunteered to participate in this study. Body density and percent body fat were calculated from BOD POD measurements of body mass and body volume. Wearing single layer limb length compression apparel to compress body hair increased body mass by an average of $0.67 \mathrm{lb}$. $( \pm 0.05)$. Compared to wearing only compression shorts, covering exposed body hair resulted in a reduction in body volume measures; thus, body density was calculated as higher in the LC apparel condition. The mean percentage of body fat in the LC condition $(13.99 \pm 6.64 \%)$ was significantly lower than the mean percentage of body fat in the CS condition $(16.76 \pm 6.27 \%, p<0.001)$. The results of this investigation demonstrate that covering exposed body hair by wearing single layer limb-length compression apparel can result in significantly different measurements of percent body fat in college-age males. These findings indicate that air displacement plethysmography for males while wearing limb-length compression apparel resulted in a lower assessment of body fat by an average of 2.77 percent. Based on the findings of this investigation, body hair needs to be accounted for when percent body fat is being assessed by BOD POD.
\end{abstract}

Keywords: Bod Pod, Air Displacement Plethysmography, Percent Body Fat, Isothermal Air, Hair, Compression Apparel

\section{Introduction}

Body composition is a factor that affects physical health and sports performance [1]. Establishing an accurate and repeatable baseline of body composition aids personal trainers and coaches monitoring the progress of clients and athletes [2-4].

Air-displacement plethysmograph (ADP) is a noninvasive, safe and quick method of assessing body composition $[5,6]$. The BOD POD body composition system (Life Measurement Instrument, Concord, CA) is a commercially available system that uses ADP for body composition assessment and the estimation of percent body fat [7]. Ease of use for the subject, only a basic level of technical expertise required of the investigator, along with quick results are additional advantages of using the BOD POD for body composition measurements [4, 8, 9].

The BOD POD is used in a variety of settings because it can accommodate diverse populations [10-15]. Previous research supports the reliability of estimates of body composition by the BOD POD [2, 5, 6, 8, 15-18].

Body volume is the primary measurement from the BOD POD; although it is estimates of percent body fat that are of primary interest from BOD POD measures [19]. Previous findings indicate that the type and tightness of apparel worn in a BOD POD can affect estimates of body volume and thus, 
body composition estimates [20]. In 2000, Rettig concluded that wearing cotton or nylon shorts was acceptable for males, but Hull and Fields (2005) reported that cotton shorts underestimate body fat percent compared to spandex shorts in males [21, 22]. Vescovi, Zimmerman, Miller and Fernhall reported there was minimal difference between body composition measurements wearing a swimsuit or nude, but that clothing (hospital gown) had a significant effect on body composition measurements by BOD POD [23].

Apparel that is tight fitting provides more accurate estimates of body volume, body density and body fat than loose-fitting clothing [20, 24]. Peeters and Claessens acknowledged that wearing minimal clothing may be viewed as uncomfortable or undesirable by some participants [25]. Vescovi, Zimmerman, Miller and Fernhall acknowledged that it may be necessary to allow BOD POD participants to wear clothing that varies from the recommended apparel [23].

Differences were also found in body volume when subjects were measured wearing different swim caps [26]. Regarding the compression of scalp hair, Peeters and Claessens concluded that attention should be paid to optimal compression of isothermal air trapped in scalp hair when assessing body composition by BOD POD [26].

The BOD POD measures an individual's body volume within its chamber. Body volume measurements are made under adiabatic conditions; however, some air is isothermal [5]. Potential sources of isothermal air are present in the lungs, body surface area, clothing, and body hair [27, 28].

Because the isothermal nature of body hair makes it more compressible, body hair can cause a greater pressure change to occur during body volume measurements [1, 11]. An increase in the pressure changes results in a decreased body volume measurement for the individual being assessed [23, 29]. Placing a smaller volume in the density formula will produce a greater body density and create a lower percent fat estimation for a given individual.

Body hair can affect the accuracy of percent fat estimations due to the distinction between air under isothermal or adiabatic conditions [5, 28]. Body composition measures by BOD POD account for the effects of trapped isothermal air in scalp hair by having the subject wear a swim cap to compress the hair on the head. The manufacturer recommends that subjects with very little hair also wear a swim cap.

Conducting BOD POD measurements on males with facial hair and again after shaving, Higgins, Fields, Hunter and Gower indicated that hair should be considered a potential source of error in the estimation of percentage of body fat by BOD POD [27]. Because the amount of torso and limb hair varies, body hair should also be considered a source of error in measurements by BOD POD [1].

Although BOD POD user directions instruct the subject to wear a swim cap to compress the hair on the head, there are no similar recommendations to account for the effects of trapped isothermal air in other body hair. In fact, Peeters and Claessens (2011) suggested that compression of hair should be maximized in an attempt to eliminate as much isothermal air as possible; otherwise, body volume measurements may be affected [26]. In 2006, Jackson, Lyons, Bishop, Richardson and Neggers found that the accuracy of percent body fat assessed by ADP was affected by body hair [30].

Beyond facial hair and hair on the scalp, research investigating the effect of body hair on BOD POD estimates of percentage of body fat is limited. The purpose of this study was to investigate the effect of body hair on college age males on estimates of percent body fat determined by BOD POD.

\section{Methods}

\subsection{Participants}

Fifty males between the ages of 18 and 24 years (age 19.9 \pm 1.32 years; BMI $24.04 \pm 2.9 \mathrm{~kg} / \mathrm{m}^{2}$ ) volunteered to participate in the study. All participants were recruited from flyers posted on campus. Inclusion criteria required all participants to be facial hair-free males. Approval was obtained from the Furman University Institutional Review Board for human use and written informed consent was obtained before all measurement sessions. The participants received a full explanation of the nature, purpose, and risks associated with their participation in the study. Participants were also given an opportunity to ask questions prior to their participation. All participants completed written and informed consent prior to any measurements.

\subsection{Instrumentation}

The BOD POD (Body Composition System; Life Measurement Instruments, Concord, CA) is a commercially available dual chamber air-displacement plethysmography device for body composition assessment and the estimation of percent body fat $[5,7]$. The underlying principles, physical design and operational procedures for the BOD POD have been described elsewhere $[4,5]$.

The BOD POD is located in a 9' by 14' space with one door and no windows. Adhering to manufacturer guidelines and recommendations, all measurements were performed in a thermo-neutral environment. The door was closed for all calibrations and measurements to minimize changes in air movement and pressure changes.

Prior to all measurement sessions, the BOD POD was calibrated using a 50.280-L cylinder following manufacturer's guidelines.

Height was measured to the nearest quarter inch using a stadiometer (Seca 216, Chino, CA, USA). Subjects stood erect, without shoes, and with their hands at their sides. Height was recorded at the end of a normal inspiration [31].

Prior to entering the BOD POD, each participant was weighed on a calibrated digital scale (Tanita Corporation, BWB 627A, Japan) that is connected to the BOD POD. Body mass determination was made for each trial with the volunteers who were wearing the apparel in which they would be measured while inside the BOD POD. Body mass was measured to the nearest 0.001 pounds using the calibrated digital platform scale. 
Body volume is a measure of body size [32]. Body volume was evaluated with the BOD POD (version 1.69). Body volume is measured as the difference in the BOD POD chamber air volume with and without the participant seated in the BOD POD $[11,33]$.

$$
\begin{gathered}
\text { Volume }_{\text {BODY }}=\text { Volume }_{\text {CHAMBER-EMPTY }}-\text { Volume }_{\text {CHAMBER- }} \\
\text { OCCUPIED }
\end{gathered}
$$

Body volume was measured by the BOD POD using the standardized published procedures [5, 6, 34]. For all trials in this investigation, body volume was measured twice by the BOD POD to ensure measurement reliability for each trial as per manufacturer guidelines. If the two measurements differed by more than $150 \mathrm{ml}$, a third measurement was completed.

Body density was calculated from the measurements of body mass and body volume $[10,35]$.

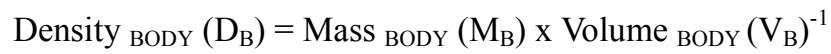

After the measures of body volume, the calculated body density was converted to percentage of body fat by the appropriate population-specific two-component model equation recommended by the BOD POD system $[4,9,19]$.

Davis et al. concluded that BOD POD measurements of thoracic gas volume (TGV) were reliable and valid for healthy adult males [34]. Miller reported that nearly 10 percent of participants were unable to properly complete the TGV measurement procedure [36]. Further, previous studies have reported no significant differences in measured TGV compared to predicted $\operatorname{TGV}[6,36,37]$; therefore, for this investigation, the predicted $\mathrm{TGV}$ was used for the measurement of body volume.

\subsection{Protocol}

To determine if exposed body hair resulted in a difference in percent body fat as measured by the BOD POD, individuals were tested in two conditions; wearing compression shorts [CS] and a swim cap [as suggested by the manufacturer] and wearing long compression apparel [LC (single layer limb length)] and a swim cap.

Single layer limb length compression apparel was worn to compress body hair and mitigate the effect of trapped isothermal air present in body hair. Since there was no mechanism in this investigation to account for facial hair, only clean-shaven men were eligible to participate. All BOD POD assessments were completed following manufacturer guidelines (previously described [6, 37].

Following BOD POD suggested protocols, participants were asked to avoid eating and drinking for three to four hours prior to their scheduled testing session. Volunteers were also asked to avoid strenuous exercise 2 hours prior to their scheduled BOD POD session. All volunteers were asked to void their bladder prior to reporting to their scheduled session.

For this study, participants completed two (2) BOD POD assessments. Study volunteers were measured while they wore form-fitting single-layer compression shorts (CS) and a swim cap (Figure 1). Study volunteers were also measured wearing form-fitting limb length single-layer compression apparel (LC) and a swim cap (Figure 2). The two measurement conditions were counter-balanced by random assignment to account for a potential order effect.

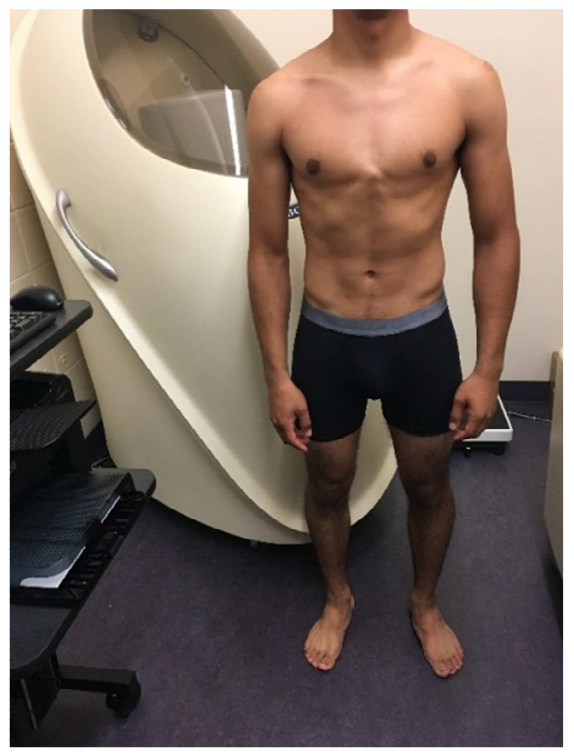

Figure 1. Compression Shorts (CS).

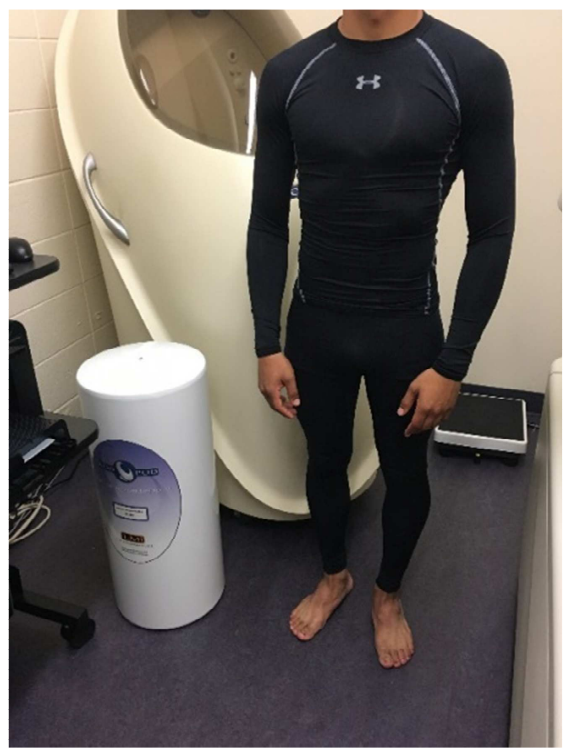

Figure 2. Limb Length Compression (LC).

Volunteers for this study were instructed to arrive for their scheduled measurement session wearing form-fitting singlelayer compression shorts (CS). For the LC measurements, participants were provided long (limb length) single-layer compression apparel. A variety of sizes was available so that each participant was able to wear the appropriate size long sleeve and long leg compression apparel. Noreen and Lemon found that the weight scale is sensitive enough to detect metabolic and evaporative mass loss [38]. In the Noreen and Lemon investigation, measurements were separated by 15 to 30 minutes. For this investigation, the two conditions (CS and 
LC) were measured consecutively (within 5 minutes of each other); in fact, the BOD POD session was completed within one 20 minute session in order to avoid the possible influence of changes in body core temperature and body mass.

Participants were instructed to sit still, with hands on their thighs and breathe normally during the 50 second measurement period. Peeters found that subject positioning within the BOD POD affected the amount of exposed skin and measurements of body volume and estimate of percent body fat [29]. For the second measurement sequence, participants were reminded to position themselves in the BOD POD as they were positioned for the first measurement condition. The same latex swim cap was worn for the two assessments.

The long sleeve and long leg compression apparel was laundered after each participant measurement session and prior to the arrival of the next scheduled volunteer.

\subsection{Statistical Analysis}

A two-sample F-test was used initially to confirm equal variances for the different measures. Estimates of body mass, body volume, body density and percent body fat wearing form-fitting single-layer compression shorts and a swim cap (CS; considered criterion method) and the single layer long sleeve and long leg compression apparel (LC) were compared using a paired t-Test for means. The alpha level for statistical significance was set at $\mathrm{P}<0.05$. Regression analysis was used to determine the agreement between the two apparel schemes. Pearson correlation was also used to indicate the relationship between the two conditions (different lengths of form-fitting apparel).

\section{Results}

Mean, standard deviation and range of the physical characteristics of the volunteers for this study are presented in Table 1.

Table 1. Participant characteristics $(n=50)$.

\begin{tabular}{lll}
\hline Anthropometric & Mean \pm SD & Range \\
\hline Age (yrs.) & $19.96 \pm 1.32$ & $18-24$ \\
Height (in.) & $70.99 \pm 3.38$ & $65.4-80$ \\
Body Mass (lb.)* & $172.415 \pm 26.36$ & $118.9-221.5$ \\
Body Mass Index $\left(\mathrm{kg} / \mathrm{m}^{2}\right)^{*}$ & $24.04 \pm 2.92$ & $18.9-33.6$ \\
\hline
\end{tabular}

* Criterion method wearing compression shorts and a swim cap.

Table 2 provides means and standard deviations for the two different apparel schemes as well as the p-value comparing all measurements.

Table 2. BOD POD measurements for the two different apparel schemes.

\begin{tabular}{lllll}
\hline Apparel scheme & & & & \\
\hline BOD POD Measure & CS & LC & p-value & correlation \\
\hline Body Mass $(\mathrm{lb}$ ) & $172.415 \pm 26.36$ & $173.093 \pm 26.39$ & $\mathrm{p}<0.001$ & 0.999 \\
Body Mass Index $\left(\mathrm{kg} / \mathrm{m}^{2}\right)$ & $24.04 \pm 2.92$ & $24.13 \pm 2.93$ & $\mathrm{p}<0.001$ & 0.999 \\
Body Volume $(\mathrm{L})$ & $73.69 \pm 11.56$ & $73.54 \pm 11.54$ & $\mathrm{p}<0.001$ & 0.999 \\
Body Density $\left(\mathrm{g} / \mathrm{cm}^{3}\right)$ & $1.0618 \pm 0.0151$ & $1.0683 \pm 0.0161$ & $\mathrm{p}<0.001$ & 0.981 \\
Body Fat $(\%)$ & $16.76 \pm 6.27$ & $13.99 \pm 6.64$ & $\mathrm{p}<0.001$ & 0.987 \\
\hline
\end{tabular}

Values are Mean $\pm \mathrm{SD}$.

$\mathrm{CS}=$ Compression Shorts; $\mathrm{LC}=$ limb length single layer compression.

Figures 3 through 6 are scatterplots of the data of the two apparel schemes for the BOD POD measures.

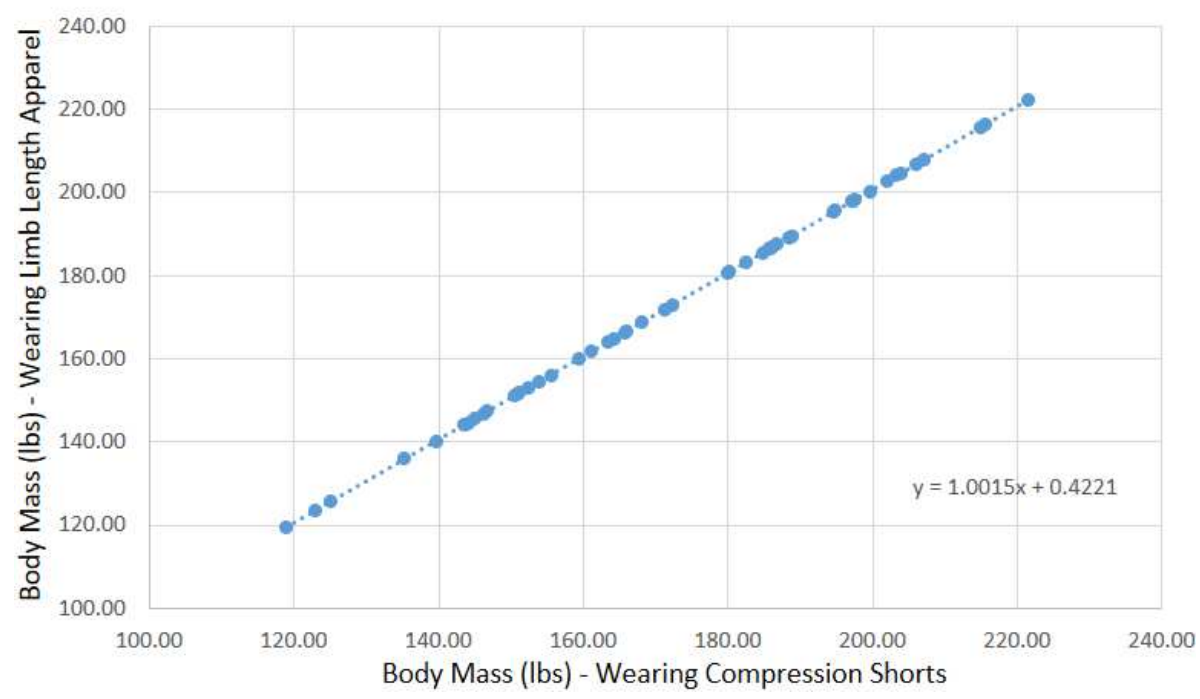

Figure 3. Apparel Scheme (Compression Shorts vs. Limb Length Apparel) and Body Weight 
Scott Murr and Alex Hultstrom: Effects of Body Hair on College-Age Males on Body Composition Measurements by BOD POD

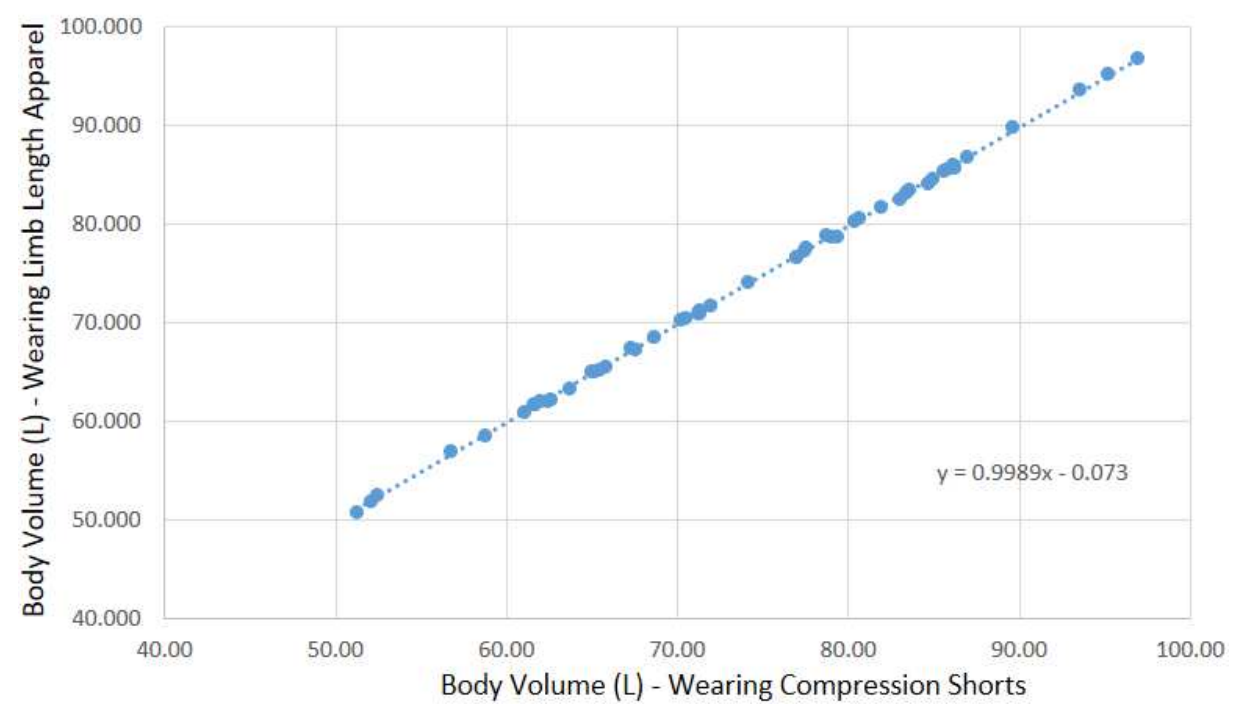

Figure 4. Apparel Scheme (Compression Shorts vs. Limb Length Apparel) and Body Volume.

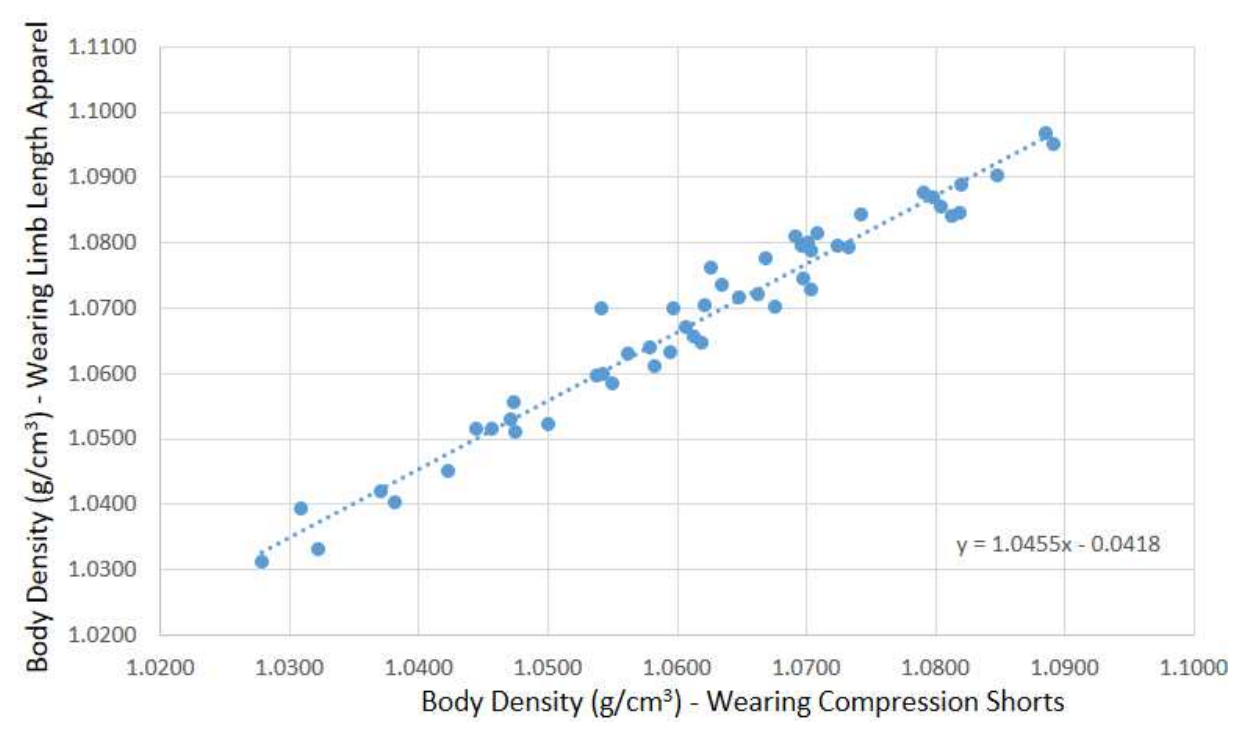

Figure 5. Apparel Scheme (Compression Shorts vs. Limb Length Apparel) and Body Density.

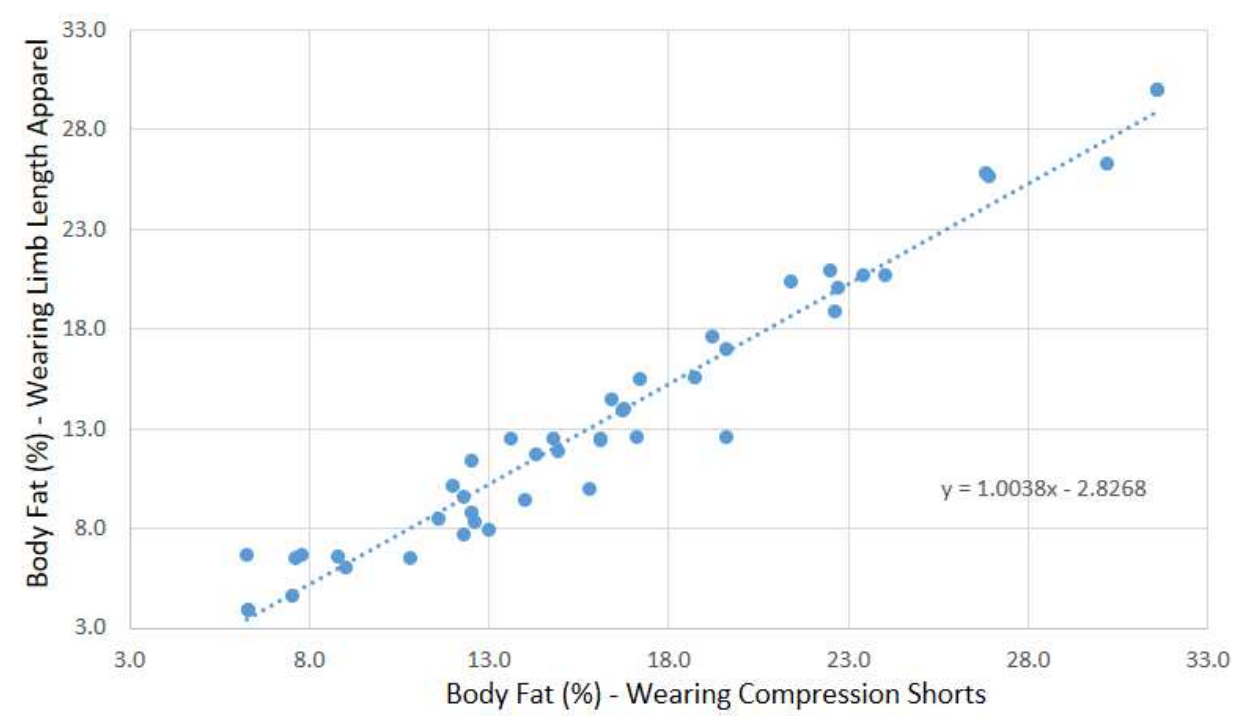

Figure 6. Apparel Scheme (Compression Shorts vs. Limb Length Apparel) and \% Body Fat. 


\section{Discussion}

This is the first investigation to examine the effect of body hair on males on BOD POD measurements. Measurements in the two different apparel schemes (CS vs. LC) were compared to determine the impact of exposed body hair on males on estimates of percent body fat determined by the BOD POD.

There was a statistically significant difference $(\mathrm{p}<0.001)$ in body mass between the two apparel schemes. Each study participant's weight increased by an average of 0.67 pounds (weight increase ranged from +0.57 to +0.77 pounds) when wearing the longer apparel. The regression coefficient was 1.0015 (Figure 3) and the intraclass correlation coefficient for measures of body mass was 0.999 .

Frequently used to assess body size, body mass index (BMI) is a quick and simple calculation of weight to height ratio. As an individual's body mass increases, their calculated BMI increases. Weighing more dressed in the single layer long sleeve and long leg compression apparel, BMI increased for each volunteer. Likewise, the intraclass correlation coefficient of measures of body mass was 0.999 . While the differences in calculated BMI may be minimal between the two conditions, BMI is often used to classify individuals (e.g. "normal", "overweight", "obese") and one tenth can make a difference in an individual's classification.

In this investigation fifteen, or 30 percent of the volunteers, who were wearing the form-fitting single-layer compression shorts (CS) would be considered "overweight" or "obese". When wearing the form-fitting limb length single-layer compression apparel (LC), seventeen (34\%) of the volunteers would be considered "overweight" or "obese." What an individual wears when being weighed can affect how their results are interpreted.

Exposed body hair resulted in a higher body volume compared when body hair was covered and compressed. Body volume is a measure of body size [32]; thus, those with exposed body hair are measured by BOD POD as larger in size compared with when their body hair is covered and compressed. While the regression coefficient was 0.9989 (Figure 4) and the intraclass correlation coefficient for measures of body volume was 0.999 , there was a statistically significant difference $(\mathrm{p}<0.001)$ in body volume between the two apparel schemes. Exposed body hair makes a difference in BOD POD measures of body volume. Exposed body hair resulted in a larger body volume by an average increase of 0.15 liters.

Body mass and body volume are used to determine body density. Compared to wearing only compression shorts, covering exposed body hair resulted in an increase in body mass and a reduction in body volume measures; thus, body density was calculated as higher in the LC apparel scheme. There was a statistically significant difference $(p<0.001)$ in body density between the two apparel schemes. Just as Fields, Higgins and Hunter reported a same-day repeated measures of body density intraclass correlation of 0.98 , results of this study found an intraclass correlation coefficient for measures of body density of 0.999 (Table 2) [39].

With a statistically significant difference in body density between the two apparel schemes, there was a corresponding significant difference $(p<0.001)$ in estimates of percent body fat between the apparel schemes. Estimates of percent body fat were lower for all volunteers when wearing limb length apparel covering exposed body hair. Covering exposed body hair resulted in an average reduction in percent body fat by 2.77 percent (range $0.3 \%$ to $7.0 \%$ ) when measured by BOD POD. The amount of body hair exposed when being measured by air displacement plethysmography can affect how their results are interpreted.

Results indicated significant differences in body composition measures for participants when they were wearing CS compared to LC. Body mass and body density were greater when body hair was covered compared to the criterion method wearing shorts and a swim cap. Body mass was higher by a mean difference of 0.67 pounds wearing apparel to cover hair on the torso and limbs. Due to differences in measures of body volume, body density was calculated as higher by a mean difference of $0.0065 \mathrm{~g} / \mathrm{cm}^{3}$. Thus, percent body fat was lower when wearing the long single layer limb length compression apparel and a swim cap by a mean difference of 2.77 percent.

Air trapped in hair is isothermal and is compressible during body volume measurements by ADP [29]. A decrease in body volume results in an increase in the calculation of body density which results in a decrease in estimates of percent body fat. Wearing tight fitting apparel to compress air trapped in body hair may minimize the errors in body volume measurements. Hull and Fields' study demonstrated that small changes in isothermal air can have an impact on body composition measurements [22].

Previous studies have investigated the impact of scalp and facial hair on body composition measurements by BOD POD. Body composition measurement procedures for BOD POD require a swim cap for all participants. Higgins, Fields, Hunter and Gower suggested that men remove all facial hair for body composition testing by BOD POD [27]. Fields, Higgins and Hunter indicated that air trapped within clothing and air trapped within body hair are sources that are "isothermal-like air" [39]. Just as a swim cap is used to compress scalp hair, the results of this investigation suggest that covering and compressing body hair is also necessary for assessing percent body fat by air-displacement plethysmography.

Haynes, Miller and Susa found that clothing effects ADP body composition measurements [40]. They found that females wearing capri-length spandex pants resulted in a lower percentage of body fat (just less than one percent). King et al. suggested that investigators standardize attire for body composition measurements by BOD POD [1].

Assessing body composition by BOD POD on 15 males, Jackson, Lyons, Bishop, Richardson and Neggers reported a mean body fat of $20.7 \pm 7.8 \%$ for the control apparel scheme 
and a mean body fat of $18.1 \pm 8 \%$ when subjects wore a fullbody lycra-type suit [30]. Mirroring those results, findings in this investigation found a mean percent body fat of $16.76 \pm 6.27 \%$ when college-age males were measured wearing compression shorts [CS] and a swim cap [as suggested by the manufacturer] and a mean percent body fat of $13.99 \pm 6.64$ when wearing single layer limb length apparel (and a swim cap).

A follow-up study with a large and more diverse population may help determine if the differences found in body composition measurements were due to compressing body hair or the apparel itself. For this investigation, the limb-length apparel was comprised of $90 \%$ polyester and $10 \%$ lycra fabric. Having participants wear limb-length apparel of different types of fabric (e.g. lycra, polyester, cotton) would help investigators determine whether differences in body volume measurements by BOD POD were due to the type of fabric or due to exposed skin and body hair. An additional approach would be to measure volunteers in the recommended apparel scheme, have them shave and remove all body hair and then repeat the body composition measurements.

\section{Conclusion}

Wearing minimal form-fitting clothing, along with a swim cap, is the standard procedure when assessing body composition by ADP. Air trapped in scalp hair is one source of error of body volume determination by ADP; consequently, BOD POD measurement procedures require participants to wear a swim cap to compress hair. BOD POD measurement procedures do not address the issue of hair on other parts of the body.

The purpose of this study was to investigate the effect of body hair on estimates of percent body fat determined by BOD POD. Based on the findings of this investigation, if health professionals, personal trainers and coaches hope to track changes in body composition, hair on the torso and limbs also needs to be accounted for when percent body fat is being assessed by BOD POD.

The results of this investigation demonstrate that covering exposed body hair by wearing single layer limb-length compression apparel can result in significantly different measurements of percent body fat in college-age males. These findings indicate that air displacement plethysmography for males while wearing limb-length compression apparel resulted in a lower assessment of body fat by an average of 2.77 percent. Just as a swim cap is recommended to compress scalp hair, attention needs to be paid to the optimal compression of body hair when assessing percent body fat by air displacement plethysmography.

\section{References}

[1] King, G. A., Fulkerson, B., Evans, M. J., \& Moreau, K. L. (2006). Effect of clothing type on validity of air-displacement plethysmography. Journal of strength and conditioning research, 20 (1), 95.
[2] Levenhagen, D. K., Borel, M. J., Welch, D. C., Piasecki, J. H., Piasecki, D. P., Chen, K. Y., \& Flakoll, P. J. (1999). A comparison of air displacement plethysmography with three other techniques to determine body fat in healthy adults. Journal of parenteral and enteral nutrition, 23 (5), 293-299.

[3] Tseh, W., Caputo, J. L., \& Keefer, D. J. (2010). Validity and reliability of the BOD POD S/T tracking system. International journal of sports medicine, 31 (10), 704-708.

[4] Shaw, G., \& Kerr, A. (2018). Non-imaging Method: Air Displacement Plethysmography (BOD POD). In Best Practice Protocols for Physique Assessment in Sport. Springer, Singapore.

[5] Dempster, P. \& Aitkens, S. (1995). A new air displacement method for the determination of human body composition. Medicine and science in sports and exercise, 27: 1692-1697.

[6] McCrory, M. A., Gomez, T. D., Bernauer, E. M., \& Molé, P. A. (1995). Evaluation of a new air displacement plethysmograph for measuring human body composition. Medicine and science in sports and exercise, 27 (12), 16861691.

[7] Vescovi, J. D., Zimmerman, S. L., Miller, W. C., Hildebrandt, L., Hammer, R. L., \& Fernhall, B. (2001). Evaluation of the BOD POD for estimating percentage body fat in a heterogeneous group of adult humans. European journal of applied physiology, 85 (3-4), 326-332.

[8] Miyatake, N., Nonaka, K., \& Fujii, M. (1999). A new air displacement plethysmograph for the determination of Japanese body composition. Diabetes, obesity and metabolism, $1(6), 347-351$.

[9] Millard-Stafford, M. L., Collins, M. A., Evans, E. M., Snow, T. K., Cureton, K. J., \& Rosskopf, L. B. (2001). Use of air displacement plethysmography for estimating body fat in a four-component model. Medicine and science in sports and exercise, 33 (8), 1311-1317.

[10] Wells, J. C. K., \& Fuller, N. J. (2001). Precision of measurement and body size in whole-body air-displacement plethysmography. International journal of obesity, 25 (8), 1161-1167.

[11] Fields, D. A., Goran, M. I., \& McCrory, M. A. (2002). Bodycomposition assessment via air-displacement plethysmography in adults and children: a review. The American journal of clinical nutrition, 75 (3), 453-467.

[12] Bosy-Westphal, A., Mast, M., Eichhorn, C., Becker, C., Kutzner, D., Heller, M., \& Müller, M. J. (2003). Validation of air-displacement plethysmography for estimation of body fat mass in healthy elderly subjects. European journal of nutrition, 42 (4), 207-216.

[13] Ball, S. D. (2005). Interdevice variability in percent fat estimates using the BOD POD. European journal of clinical nutrition, 59 (9), 996-1001.

[14] Fields, D. A., Higgins, P. B., \& Radley, D. (2005). Airdisplacement plethysmography: here to stay. Current opinion in clinical nutrition and metabolic care, 8 (6), 624-629.

[15] Anderson, D. E. (2007). Reliability of air displacement plethysmography. The journal of strength and conditioning research, 21 (1), 169. 
[16] Collins, M. A., Millard-Stafford, M. L., Sparling, P. B., Snow, T. K., Rosskopf, L. B., Webb, S. A., \& Omer, J. (1999). Evaluation of the BOD POD for assessing body fat in collegiate football players. Medicine and science in sports and exercise, 31 (9), 1350-1356.

[17] Bailey, B. W., Tucker, L. A., Peterson, T. R., \& LeCheminant, J. D. (2001). Test-retest reliability of body fat percentage results using dual energy X-ray absorptiometry and the BOD POD. Medicine and science in sports and exercise, 33 (5), S174.

[18] Noreen, E. E., \& Lemon, P. W. (2006). Reliability of air displacement plethysmography in a large, heterogeneous sample. Medicine and science in sports and exercise, $38(8)$, 1505-1509.

[19] Gillan, M. R. (2010). Inter-Device Reliability of the BOD $P O D$ for Clinical and Research Use. (Doctoral dissertation, The Ohio State University).

[20] Shafer, K. J., Siders, W. A., Johnson, L. K., \& Lukaski, H. C. (2008). Interaction of clothing and body mass index affects validity of air-displacement plethysmography in adults. Nutrition, 24 (2), 148-154.

[21] Rettig, N. L. (2000). The effect of cotton clothing on percent fat measurements via air displacement plethysmography (BOD

https://cardinalscholar.bsu.edu/handle/handle/186807

[22] Hull, H. R., \& Fields, D. A. (2005). Effect of short schemes on body composition measurements using air-displacement plethysmography. Dynamic medicine, 4 (1), 8.

[23] Vescovi, J. D., Zimmerman, S. L., Miller, W. C., \& Fernhall, B. (2002). Effects of clothing on accuracy and reliability of air displacement plethysmography. Medicine and science in sports and exercise, 34 (2), 282-285.

[24] Fields, D. A., Hunter, G. R., \& Goran, M. I. (2000). Validation of the BOD POD with hydrostatic weighing: Influence of body clothing. International journal of obesity, 24 (2), 200-205.

[25] Peeters, M. W., \& Claessens, A. L. (2009). Effect of deviating clothing schemes on the accuracy of body composition measurements by air-displacement plethysmography. International journal of body composition research, 7 (4).

[26] Peeters, M. W., \& Claessens, A. L. (2011). Effect of different swim caps on the assessment of body volume and percentage body fat by air displacement plethysmography. Journal of sports sciences, 29 (2), 191-196.

[27] Higgins, P. B., Fields, D. A., Hunter, G. R., \& Gower, B. A. (2001). Effect of scalp and facial hair on air displacement plethysmography estimates of percentage of body fat. Obesity research, 9 (5), 326-330.

[28] Collins, A. L., \& McCarthy, H. D. (2003). Evaluation of factors determining the precision of body composition measurements by air displacement plethysmography. European journal of clinical nutrition, 57 (6), 770.

[29] Peeters, M. W. (2012). Subject positioning in the BOD POD only marginally affects measurement of body volume and estimation of percent body fat in young adult men. PLoS one, 7 (3), e32722.

[30] Jackson, J., Lyons, S., Bishop, P., Richardson, M., \& Neggers, Y. (2006). Effect of isothermal air on measurement of body composition by air displacement plethysmography. International journal of body composition research, 4 (4), 169.

[31] Lohman, T. G., Roche, A. F., \& Martorell, R. (1988). Anthropometric standardization reference manual. Champaign, IL: Human Kinetics.

[32] Duda, K., Majerczak, J., Nieckarz, Z., Heymsfield, S. B., \& Zoladz, J. A. (2019). Human body composition and muscle mass. In: Zoladz, J. A., ed. Muscle and Exercise Physiology. London: Elsevier, Academic Press; 3-26.

[33] Collins, A. L., Saunders, S., McCarthy, H. D., Williams, J. E., \& Fuller, N. J. (2004). Within-and between-laboratory precision in the measurement of body volume using air displacement plethysmography and its effect on body composition assessment. International journal of obesity, 28 (1), 80 .

[34] Davis, J. A., Dorado, S., Keays, K. A., Reigel, K. A., Valencia, K. S., \& Pham, P. H. (2007). Reliability and validity of the lung volume measurement made by the BOD POD body composition system. Clinical physiology and functional imaging, 27 (1), 42-46.

[35] Ryan, A. S., \& Elahi, D. (1996). Body: composition, weight, height and build. In: Birren, J. E. (ed.). Encyclopedia of Gerontology. Academic Press: San Diego, CA, pp. 193-201.

[36] Miller, J. M. (2016). Measured versus predicted thoracic gas volume in college students. Medicina Sportiva: Journal of Romanian sports medicine society, 12 (2), 2772.

[37] McCrory, M. A., Molé, P. A., Gomez, T. D., Dewey, K. G., \& Bernauer, E. M. (1998). Body composition by airdisplacement plethysmography by using predicted and measured thoracic gas volumes. Journal of applied physiology, 84 (4), 1475-1479.

[38] Noreen, E. \& Lemon, P. (2004). Reliability of air displacement plethysmography in a large sample. Medicine and science in sports and exercise. 36 (5): S70.

[39] Fields, D. A., Higgins, P. B., \& Hunter, G. R. (2004). Assessment of body composition by air-displacement plethysmography: influence of body temperature and moisture. Dynamic medicine, 3 (1), 1-7.

[40] Haynes, S., Miller, J., \& Susa, K. (2019). Effect of Capris in validity of air-displacement plethysmography in female college students. International journal of exercise science, 12 (4), 1315-1322. 